over 28 inches of stemming, and $1 \mathrm{I}$ inches in the other holes, leaving about 20 inches for stemming.

The coal-dust is strewn upon the floor of the gallery from the face towards the open end in a layer of about I'I7 inch thic's immediately before firing the shots. The weight of dust in each ten yards of length is about thirty pounds. It has been found in practice that, notwithstanding the upward direction of their axes, the shots next the floor produce the greatest disturbance of the coal-dust and give rise to longer coal-dust flames than any of the others.

In all the experiments witnessed by Mr. Lewis and myself, one shot-hole cnly, namely, one of the two next the floor, was charged and fired. The charge consisted of 230 grammes of blasting-powder each time, and the tamping was damp clay. Both ends of the branch gallery were closed with a double board brattice 1.96 inch thick.

In the first experiment neither coal-dust nor fire-damp was employed, and the flame of the shot was seen through the windows to be a little over i 3 feet long.

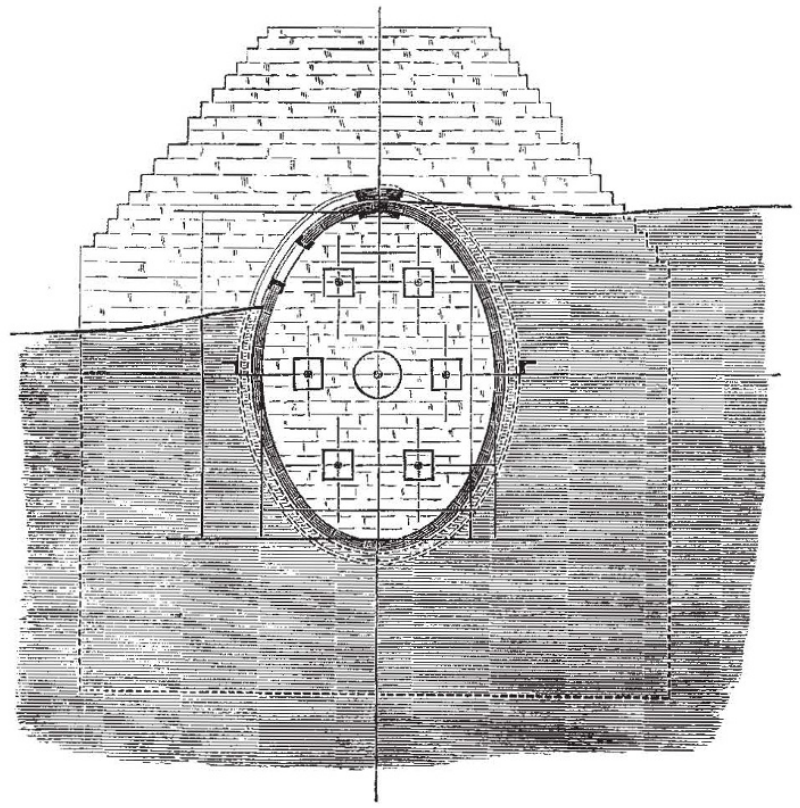

In the second experiment a length of 65 feet of the floor of the main gallery was strewn with coal-dust from Camphausen Colliery in the Saarbrücken mining district. The shot gave rise to a loud detonation, and the resulting flame filled the gallery to a distance of $88 \frac{1}{2}$ feet. When the thick black after-damp had been drawn off by means of two of Korting's exhausters, placed over two of the safety-holes and worked with compressed air, it was found that the inner brattice of the branch gallery had been bro'en, and small globules of coke were observed lying on the surface of the remaining coal-dust.

In the third experiment a length of 130 feet of the floor of the main gallery was strewn with coal-dust from Pluto Mine in Westphalia. When the shot was fired, the flame traversed the whole length of the gallery with great velocity, and came out at the open end to a distance of I 6 feet, being thus altogether 183 feet long. Notwithstanding the entire absence of fire-damp, this was a true explosion of the most violent kind, and the clouds of afterdamp which streamed from every opening darkened the air in the neighbourhood of the gallery for two or three minutes. The brattice at the inner end of the branch gallery had not been replaced before this experiment, and the one at its outer end was broken into small frag- ments, some of which were thrown to a distance of 115 feet. The flame was also seen to emerge from the branch gallery to a distance of several yards. The coal-dust remaining on the floor after the explosion was covered with a sooty film, in which coke globules were found embedded.

The brattice at both ends of the branch gallery was now replaced, and the floor of the main gallery swept clean as usual. In the fourth and last experiment coaldust from Pluto Mine was strewn on the floor for a distance of 65 feet from the face. A diaphragm of prepared canvas was fastened in the gallery at the point where the space inclosed between itself and the face amounts to 705 cubic feet.

A volume of $35 \frac{1}{4}$ cubic feet of fire-damp was introduced into this space, and complete diffusion was effected by beating the air with cloths. The mixture of fire-damp and air thus obtained is not inflammable or explosive by itself, and shows a cap of only $1 \frac{5}{16}$ inch high on the reduced flame of a safety-lamp. The firing of the shot produced a flame 190 feet long, accompanied by a report like a thunder-clap. The inner brattice of the branch gallery was broken, and drawn several yards into the main gallery, but the outer one remained intact.

Some idea of the great force of the two last explosions may be gathered from the following facts :-An ordinary mine railway, beginning on a level with the floor of the main gallery, extends away from its open end in the direction of its length, and ascending at an angle of $4^{\circ}$. An ordinary mine waggon, loaded with iron so as to weigh altogether $55 \frac{1}{2} \mathrm{cwt}$., was standing on the rails at the mouth of the main gallery when the shots were fired. When the third shot was fired, it was driven up along the rails to a distance of 23 feet, and when the fourth shot was fired, it was literally hurled along the railway by the force of the explosion to a distance of $52 \frac{1}{2}$ feet, being driven off the rails and running on the ground for the last six feet. The boards constituting the end of this waggon next the gallery were broken, but not torn off. A small beam 4 inches square, bolted across the rails at the mouth of the gallery, so as to form a stop for the waggon, was torn from the bolts which held it, and sent flying after the train. Lastly, a shower of stones and debris was raised by the blast which swept out of the mouth of the gallery, and some of the pieces carried upwards of Ioo feet.

The foregoing facts appear to me to be well worthy of the attention of all who have any interest in the prevention of explosions in mines. W. GALLOWAY

\section{FLOWERS OUT OF SEASON}

THE untimely flowering of trees and shrubs, like the occurrence of the extraordinary gooseberry, is a subject which crops up at such regular intervals as almost to belie the epithet applied to it. Nevertheless, the very frequency of the comment is an indication that the matter is ill understood.

The ordinary time-rate for the production of new cells, new leaves, new flowers, and so on, varies as we see within wide limits. Equally obviously those limitations are imposed by the conjoint effects of inheritance and of external conditions, such as climate or food, or both. An annual plant rushes through its life in hot haste as it were: save and except in the seeds of such plants there is comparatively little building up or maturing of new tissues to be done, and proportionately still less stores of potential food to be accumulated. If, on the one hand, the requirements of such plants are less than in the case of perennials, their exigencies are, on the other hand, more pressing. What they take from the soil, or atmosphere, what power they derive from solar light and heat, must be got quickly or not at all. One illustration of this is afforded by the paucity of annual species in the Arctic regions or at high altitudes. Neither heat nor light is absolutely deficient in such situa- 
tions, but the length of time during which they are available is too short to allow annuals to profit by a sufficiently large aggregate to enable them to mature their seeds. Before they can accomplish their purpose, they are overtaken by frost and their activity is put a stop to. The energy of perennials, it is true, may be checked in the same manner, but they have been enabled, before the evil day arrived, to lay up stores of nutriment available for use when the increasing heat and light of the following year shall once more quicken their activity. The work to be done is spread over two or more seasons instead of one, and the chances of success are thus correspondingly enhanced. But if we suppose the conditions to be uniformly and continuously favourable, the abrupt cessation of growth will no longer be manifest, the annual will cease to be an annual, the perennial will not die down in winter, the growing points of the buds will not incase themselves in scales, vegetation will be continuous. Such halcyon conditions find their nearest realisation in moist equatorial climates like that of the Malay peninsula and adjacent islands. But even there the realisation is not perfect. Something happers to disturb the balance; and even if the conditions are generally uniform there is always the idiosyncrasy of individual plants to form a disturbing factor. Again, such conditions, though favourable to the continuance of vegetation, are less propitious to the establishment of fructification. The formation of stem, leaf, flower, even of fruit, is one thing, the maturation of the seed and of the embryo-plant within it is another; and the conditions propitious to either are correspondingly different. The ripe seed makes in proportion larger demands on the plastic matters formed as a result of metabolism, and has almost invariably the same composition according to its species, but this cannot be said with equal truth of any other part of the plant.

Again, the conditions for growth, that is, mere increase in bulk, are different, in degree at least, from those which favour progressive development or metamorphosis. Speaking in general terms, it may be said that vegetation approaches its end where fructification shows signs of commencement. There is indeed no fixed line of demarcation to be drawn, but while morphologically there are gradations and intermediate forms, physiologically there are also transitions, and periods of instability. It is easy to understand how this happens, and how it is the divergences are not greater. These matters indeed partake so much of the nature of truisms, that some apology might almost be needed for insisting on them, were it not that they are absolutcly essential for the due comprehension of the phenomena of untimely blooming.

It is also desirable to draw attention to the fact that there is naturally a wide range in the period during which vital activity manifests itself even in individuals of the same species, and as these individuals vary in colour, stature, \&c., even when derived from the same stock, so others may vary in their " time-rates." This is specially noticeable in the case of the horse-chestnut, and is perhaps more often manifest in the form of precocious development in spring than in that of tardy growth in autumn. In most cases the plant has to attain a certain age before it produces flowers, but occasionally we find individuals so precocious that they are scarce out of the seed bcfore they burst into flower. A cocoa-nut has thus been seen in flower while the husk of the fruit was still attached to it. Gardeners, according to their requirements, have freely availed themselves of these individual differences by selecting for perpetuation late or early varieties. The whole subject of the "chronometry of life," it may here be mentioned, formed the text of a valuable lecture by Sir James Paget, at the Royal Institution, many years ago.

Cases of unseasonable blossoming may be ranged under three heads, according as growth and development are : (I) prolonged beyond the ordinary time; (2) premature or manifested aforetime; (3) renewed after a short interval of arrest. Categories (2) and (3) differ in detail rather than in essence, as will be explained further on.

Taking the cases of continuous or prolonged growth first, it is easy to see that many of them are due to a continuance of favourable conditions. A long spell of summer without excessive heat or drought will insure a longer period of blooming; flower will succeed to flower so long as the weather and the natural changes in the tissues of the plant, according to age, are held in abeyance. How small are the exigencies of some plants in these matters may be illustrated by the fact that there are few days in the year when a daisy or a white deadnettle may not be found in bloom, at least in the southern half of England. It is necessary, however, to introduce some qualification, because one has only to look into one's garden to see that in spite of apparently favourable conditions many plants are not to be induced to continue blooming. Although in duration perennial, in the matter of flowering they behave as annuals. Something in their organisation forbids the prolongation of the blooming period. That this is so is at Ieast rendered highly probable by the circumstance that the same reticence is exhibited under cultivation. As an illustration of an opposite character, may be mentioned the prolongation of the blooming period even under relatively adverse circumstances which has been brought about by the art and selection exercised by the gardener. Take roses, for instance, only one of many that might be cited. Our fathers had to be content with what we now call summer roses, roses of great beauty and exquisite fragrance, but which they must have wept to see "haste away so soon." Nowadays, the case is very different, there is a whole legion of so-called "hybrid perpetuals" marked in the catalogues of the nurserymen as H.P. By their agency a second crop of roses is assured, while some will continue in favourable seasons to expand their blooms in succession up to Christmas. This prolongation of the flowering season has been brought about by combining by means of hybridisation the robust qualities of European roses with the continuous blooming tendencies of the Indian rose. Many varieties of pear, the common laburnum, the Wistaria, Weigela, the hybrid Berberis stenophylla, some rhododendrons, currants (Ribes), exhibit this phenomenon, the flowers being produced on the ends of more or less prolonged shoots, as strawberries under like circumstances produce their flowers on the ends of the "runners" of the year.

The premature development of flowers in autumn has a better title to be called unseasonable, because the phenomenon is really due to the unfolding of flowers which, under ordinary circumstances, would remain passive till the following spring. There is not, as in the former case, a new formation or a continuous growth, but merely what the French appropriately call fleuraison anticipée. And here for a moment it may be allowable to call attention to an essay of Linnæus entitled Prolepsis Plantarum, little read nowadays, although based on facts, and containing much that is still worthy of consideration. For him a flower was a shoot with lateral outgrowths, a morphological conception that would still satisfy a German transcendentalist. But, further, this shoot and its outgrowths were supposed to represent the outcome of six ordinary years' work contracted into one. A flower was, according to this theory, a shoot in which the differentiation of parts instead of being spread over six years was hurried on and completed within one season. For Linnæus leaves represented the work of one year, bracts that of the following one, sepals of the third, petals of the fourth, stamens of the fifth, and the pistil that of the sixth year. It is not necessary to discuss the morphological aspects of this theory, but it is relevant to our present purpose because it emphasises the relation of leaf-shoot to flower - a relation enunciated about the same 
time, and independently one of the other, by Wolf and by Linnæus, and thirty years before Goethe propounded a similar notion. Moreover, it brings into prominence not only the morphological relation of shoot and flower, but one manner in which the time of production of the shoot and of the flower respectively may be varied, a subject having an immediate bearing on the question of unseasonable flowering. If, says Linneus (Prolepsis, §iii.), "a shrub which has been grown in a pot, and has borne flower and fruit every year, be transferred to richer soil in a hot-house, it will produce for many years numerous leafy shoots, but no fruit. From which it may be inferred that the leaves are produced from the same source whence the flowers previously sprang, and so in turn what now tends to form leaves would, by this agency of Nature, be converted into flower if the same tree were again placed in a pot so as to confine the roots; hence gardeners desirous of obtaining a more plentiful crop of strawberries, cut the fine roots of the plants in spring before they transplant them, in the hope that they will produce more abundant flowers and fruit." Here we see the same principle laid down as that upon which gardeners act when they wish to secure flower and fruit by cutting off the supplies, and thus making the plant, to a greater degree, dependent on the elaborated reserve stored up in their tissues. This is effected by growing plants in small pots, root-pruning, transplanting, ringing, and other processes, all of which tend to diminish root-absorption, and by disturbing the balance between it and other processes, to check vegetation, and in so far to promote the formation of flower. Charles Martins relates the production on a very large scale of inflorescence on the Agave, in Algeria, as the direct consequence of the excision of the leaf-buds by a troop; of French cavalry, who hacked the plants with their sabres as they passed, and thus, by preventing or checking growth in one direction, stimulated it in another. In like manner I have seen flowers produced on the "suckers" of Ailanthus glandulosa when the plant was quite young, on the roots of Pyrus japonica, and on a sucker of Agave, as the result of injury, probably in all, certainly in some, of the instances.

The frequent production of flowers out of season on newly transplanted trees is accounted for in like manner. But many trees are flowering this autumn which have not been slashed with sabres nor moved by more peaceful weapons. Cne such tree, a horse-chestnut, I lately (September) saw, in which one limb, and one only, was full of young leaves and flowers, while the remaining limbs were fast losing their foliage. The reason for this partial production of bloom I was not able to divine ; possibly it may have had some relation to injury to a certain portion of the root-system in more or less direct connection with the particular branch, but I have no evidence to offer in support of such a guess.

In speaking previously of one modification of unseasonable flowering dependent on activity protracted beyond the customary period, it was mentioned that the flower was in such instances developed at the ends of long slender shoots formed during the course of the summer. In such cases the shoot ends in a flower-bud instead of a leaf-bud as is usually the case. The conditions are no longer favourable for the extension of the shoot, and the energy of growth is diverted to the production of flower. But in the laburnum, in many fruit-trees, such as the apple and pear, the fruits are normally borne on short thick branches called by the gardeners "spurs." These are very interesting physiologically, as possessino intermediate transitional characteristics, such as those before alluded to, between vegetation and seed-production. In form, these spurs are short and thick, with very narrow interspaces between the leaves, and they bear a cluster of buds which ultimately all develop into flowers, or in which the central and terminal one is a leaf-bud. Internally these spurs are soft and spongy, with a great prepon- derance of cellular over fibro-vascular or woody tissue. The cells are moreover filled with starch. We have evidently here got to do with store-places, analogous to that furnished by the tuber of the potato and other formations, in which food, or matter capable of conversion into food, is stored up for future use at the growing points; in this case for the formation of fruit. Flowers are occasionally produced on these spurs out of due season: the flowerbud destined for a following season bursts into activity this year, affording an instance of a true fleuraison anticipée; but more often, according to my observations, when an untimely flower is produced (especially in the apple), it is from the development of a flower in the central bud of the spur, which is usually a leaf-bud as above stated. In such a case, then, we have not only an alteration in the character of the bud, but a change in the period of its expansion. A converse illustration to that just given is afforded by a case recorded by Mr. Berkeley, in which a bud of a walnut, which in the ordinary course of things should have produced a female inflorescence in the following spring, was developed in the autumn as a leafy shoot.

Renewal of growth after temporary arrest, "recrudescence" as it is sometimes called, occurs normally in the pine-apple, Eucomis, Metrosideros, and other plants. Abnormally, I have met with it in Cytisus nigricuns, the common wallflower, Enothera, and many others. It hardly differs from the first category mentioned in this note except in the fact that the new growth is the direct continuation of the old and not an entirely new lateral formation. It differs from the terminal bud of a "spur.' in that the latter is normal as to position even if developed out of season, whereas in the class of cases now under consideration the activity of the growing point, which usually ceases with the development of the last flower, is exceptionally continued.

One other circumstance deserves mention, and that is the rarity with which true fruit, or at least ripe seed, is produced as a result of these untimely flowers. Sometimes, of course, ripe seed is produced; a plum is before me as I write the seed of which is as perfect, to all appearance, as that of the first crop could have been. But in the majority of the pears and apples which come under one's notice at this unseasonable period, the fruit is there (in the popular sense), but the core, which is in a botanical sense the true fruit, is absent, or, if present, the seeds it contains are usually abortive. Botanical readers will readily see the morphological reason why, and physiologists will recognise that in such cases the deviation from the ordinary course is not so great as it appears upon the surface, and the action of the "environment" is not so potent as it appears to be at first sight.

To sum up: these cases of unseasonable flowering appear to be due either to continuous growth and development, to renewal of growth after a longer or shorter period of arrest, or to the development of a flower-bud in the place of a leaf-bud. What produces these changes? To this no more precise answer can be given than has already been atforded. The absolute nature of the change, structurally and morphoIngically, depends upon the nature of the inducing causes, and varies accordingly; the degree of change may depend simply on the increased or prolonged intensity of action of the same causes which promote natural growth.

Maxwell T. Masters

\section{NOTES}

The Washington Prime Meridian Conference closed on November I. Protocols were approved, which will be made the basis of an international convention, fixing Greenwich as the prime meridian.

Manchester is determined to have the British Association in $\mathbf{1 8 8 6}$, and its invitation will almost certainly be accepted. 